\title{
The Association of Co-morbid Symptoms of Depression and Anxiety with All-Cause Mortality and Cardiac Rehospitalization in Patients with Heart failure
}

\begin{abstract}
Abdullah S. Alhurani, PhDc, MSN, BSN, RN ${ }^{\star}, 1$, Rebecca L. Dekker, PhD, RN², Mona A. Abed, PhD, RN ${ }^{3}$, Amani Khalil, PhD, RN ${ }^{4}$, Marwa H. Al Zaghal, MSN, RN, APRN ${ }^{5}$, Kyoung Suk Lee, PhD, MPH, RN ${ }^{6}$, Gia Mudd-Martin, PhD, RN ${ }^{7}$, Martha J. Biddle, PhD, RN ${ }^{8}$, Terry A. Lennie, PhD, RN ${ }^{9}$, and FAAN and Debra K. Moser, DNSc, RN, FAAN ${ }^{10}$

${ }^{1}$ University of Kentucky, Lexington, United States \& The University of Jordan, Amman, Jordan "This author takes responsibility for all aspects of the reliability and freedom from bdeias of the data presented and their discussed interpretation".

2 University of Kentucky, Lexington, United States "This author takes responsibility for all aspects of the reliability and freedom from bias of the data presented and their discussed interpretation".

3 The Hashemite University, Zarqa, Jordan "This author takes responsibility for all aspects of the reliability and freedom from bias of the data presented and their discussed interpretation".

${ }^{4}$ The University of Jordan, Amman, Jordan "This author takes responsibility for all aspects of the reliability and freedom from bias of the data presented and their discussed interpretation".
\end{abstract}

${ }^{5}$ Arabic Community College, Amman, Jordan "This author takes responsibility for all aspects of the reliability and freedom from bias of the data presented and their discussed interpretation".

${ }^{6}$ University of Kentucky, Lexington, United States "This author takes responsibility for all aspects of the reliability and freedom from bias of the data presented and their discussed interpretation".

7 University of Kentucky, Lexington, United States "This author takes responsibility for all aspects of the reliability and freedom from bias of the data presented and their discussed interpretation".

8 University of Kentucky, Lexington, United States "This author takes responsibility for all aspects of the reliability and freedom from bias of the data presented and their discussed interpretation".

${ }^{9}$ University of Kentucky, Lexington, United States "This author takes responsibility for all aspects of the reliability and freedom from bias of the data presented and their discussed interpretation".

10 University of Kentucky, Lexington, United States "This author takes responsibility for all aspects of the reliability and freedom from bias of the data presented and their discussed interpretation".

\footnotetext{
(C) 2014 Academy of Psychosomatic Medicine. Published by Elsevier Inc. All rights reserved

*Corresponding author. Abdullah S. Alhurani, University of Kentucky, College of Nursing, 509 CON, 760 Rose Street, Lexington, KY 40536-0232, United States. Tel.: +1 859 4893199; fax: +1 859323 1057. asal223@uky.edu(A.S. Alhurani).

Publisher's Disclaimer: This is a PDF file of an unedited manuscript that has been accepted for publication. As a service to our customers we are providing this early version of the manuscript. The manuscript will undergo copyediting, typesetting, and review of the resulting proof before it is published in its final citable form. Please note that during the production process errors may be discovered which could affect the content, and all legal disclaimers that apply to the journal pertain.
} 


\section{Abstract}

Background-Patients with heart failure (HF) experience multiple psychological symptoms. Depression and anxiety are independently associated with survival. Whether co-morbid symptoms of anxiety and depression are associated with outcomes in patients with HF is unknown.

Objective-To determine whether co-morbid symptoms of depression and anxiety are associated with all-cause mortality or rehospitalization for cardiac causes in patients with HF.

Method-A total of 1,260 HF patients participated. Cox regression analysis was used to determine whether co-morbid symptoms of depression and anxiety independently predicted allcause mortality and cardiac rehospitalization. Anxiety and depression were treated first as continuous level variables, then as categorical variables using standard published cut points. Patients were then divided into four groups based on the presence of anxiety and depression symptoms.

Results-When entered as a continuous variable, the interaction between anxiety and depression (HR 1.02; 95\% CI: 1.01-1.03; $p=0.002$ ) was a significant predictor of all-cause mortality in HF patients. When entered as a categorical variable, co-morbid symptoms of depression and anxiety (versus no symptoms, or symptoms of anxiety or depression alone) independently predicted allcause mortality (HR 2.59; 95\% CI: 1.49-4.49; $\mathrm{p}=0.001$ ). None of the psychological variables was a predictor of cardiac rehospitalization in HF patients whether using the continuous or categorical level of measurement.

Conclusion-To improve mortality outcomes in patient with HF, attention must be paid by healthcare providers to the assessment and management of co-morbid symptoms of depression and anxiety.

\section{Keywords}

Heart failure; Depression; Anxiety; Mortality; Rehospitalization

\section{Introduction}

In the United States, heart failure (HF) is a major public health problem that affects around 5.7 million patients, with 670,000 newly diagnosed patients each year (1).The total costs of HF in the United States are estimated to be \$37billion each year (1). Although there have been significant therapeutic advances in pharmacological and surgical treatment of HF, the one-year mortality rate of HF patients with progressive symptoms still approaches $40 \%$, which is the same for some types of aggressive cancer $(2,3)$. Even patients who have less serious HF symptoms usually experience impaired quality of life (3). The high mortality and morbidity rates associated with HF are still not well explained (4). Patients with HF simultaneously experience multiple psychological symptoms that affect health outcomes such as symptoms of depression and anxiety.

Depression is a mood disorder that interferes with an individual's ability to perform daily life activities $(5,6)$. Depression is characterized by specific symptoms such as changes in appetite, sleep disturbance, fatigue, agitation, feelings of guilt or worthlessness, and concentration problems (7-9). Depression is a significant clinical problem that is found in a 
substantial number of patients with HF; around $20 \%$ of outpatients who have HF have major depressive symptoms, and up to $48 \%$ of outpatients experience clinically significant depressive symptoms (10). Furthermore, HF patients who are depressed are two times more likely to be hospitalized and face death than those who are not depressed (11). Depression is associated with unhealthy behaviors like smoking and unsatisfactory patient compliance (12, 13). Moreover, depression is associated with pathophysiological mechanisms that negatively affect cardiac conditions, such as hypercortisolemia, impaired platelet function, and reduced heart rate variability (14-17).

Anxiety is a negative emotional state resulting from the perception of threat, and is described as the result of a perceived inability to predict, control, or gain from the threatening situation $(5,7)$. Anxiety is significantly associated with a higher occurrence of adverse cardiac events and cardiac death in the general population and in patients with coronary artery disease $(5,18)$. Anxiety also has been linked to pathophysiological mechanisms that could mediate negative outcomes such as reduced heart rate variability and baroreflex cardiac control, cardiac arrhythmias, and sudden death (19-21). Patients with HF have a $60 \%$ higher level of anxiety compared to healthy elders; $40 \%$ percent of patients suffer from major anxiety $(7,22,23)$. In addition, patients with HF tend to have higher levels of anxiety compared to other cardiac disease patients or even cancer and lung patients. There are, however, contradictory results about the association between anxiety and health outcomes in patients with $\operatorname{HF}(24,25)$.

Individually, depression and anxiety are associated with survival in HF patients; however, the association of co-morbid symptoms of anxiety and depression with morbidity and mortality in patient with HF is unknown. Thus, the purpose of this study was to examine whether co-morbid symptoms of depression and anxiety are associated with all-cause mortality or rehospitalization for cardiac causes in patients with HF.

\section{Method}

\subsection{Design, sample, and setting}

Data from this study were from the Heart Failure Health-Related Quality of Life Collaborative Registry (26), housed at the University of Kentucky College of Nursing. This is a longitudinal database that includes data from patients from across the United States and from several international sites $(n=4076)$. From this database, we analyzed data from all patients who had data on anxiety, depression, and mortality and rehospitalization outcomes $(\mathrm{n}=1,260)$. The demographics (i.e., age, gender, and ethnicity) and New York Heart Association (NYHA) class of the sample used in the current study were compared statistically to those in the registry who did not have data on anxiety, depression and outcomes. There were no differences between these two groups on these four variables. The database was accessed through the Research and Interventions for Cardiovascular Health (RICH) program at the University of Kentucky. Inclusion criteria for the original database were patients with a confirmed diagnosis of HF with impaired or preserved left ventricular systolic function. Patients were excluded if they had valvular heart disease, were referred for heart transplantation, had a history of cerebrovascular accident or myocardial infarction in 
the past 6 months, had a co-existing terminal illness. Data on mortality and rehospitalization were collected over 12 months $(27,28)$.

\subsection{Measures}

\subsubsection{Symptoms of Depression and Anxiety}

Depressive symptoms: The Patient Health Questionnaire (PHQ-9) $(29,30)$ was used to measure depressive symptoms in this study. The PHQ-9 is a 9-item, self-reported measure of depression that reflects the severity of depressive symptoms over the past two weeks. (31, 32) Patients respond to each item by using a Likert scale in which responses range from 0 (not at all) to 3 (nearly every day). The total summary score can range from 0 to 27; a higher score reflects more severe depressive symptoms. Good internal consistency, stability, construct and concurrent validity of the PHQ-9 have been supported $(28,32)$. The standard published cut point of 10 was selected in this study for PHQ-9 to identify those in the sample who were depressed and those who were not depressed (28). This cut point was reported to have $88 \%$ sensitivity and $88 \%$ specificity for diagnosing major depression.(31, 32)

Anxiety: The Brief Symptom Inventory (BSI) anxiety subscale was used to measure current symptoms of anxiety $(33,34)$. The subscale consists of 6 questions, each of which are scored by patients using a scale that ranges from 0 (not at all) to 4 (extremely). The total score is calculated by summing all 6 item scores and taking the mean. Thus, the possible range of scores for the anxiety scale is 0 to 4 with higher scores indicative of higher levels of anxiety. The BSI has demonstrated internal consistency, stability, construct and concurrent validity in other studies $(33,34)$. In this study, the Cronbach's alpha of the anxiety scale was 0.82.A standard published mean of 0.35 was used in this study for BSI to identify those in the sample who were anxious and those who were not anxious (35).

2.2.2. Mortality and Rehospitalization Outcomes-All-cause mortality, or rehospitalization for cardiac causes were the outcome variables in this study. By monthly phone call follow up and by reviewing electronic and non-electronic hospital medical records, all dates of and reasons for hospitalization and death were collected. Furthermore, death certificates were acquired to confirm the cause of death. Patients were followed for at least 12 months.

2.2.3. Demographic and clinical variables—Data on demographic variables and clinical characteristics were collected by reviewing medical records and interviewing patients. These variables included age, gender, ethnicity, and New York Heart Association (NYHA) class. The NYHA class indicates the level of functional impairment reported by patients as a result of symptoms and was rated by trained research nurses. These variables were selected because of their effects on the outcome variable as suggested in the literature $(28,31)$.

\subsection{Statistical Analysis}

Data were analyzed using SPSS software, version 20.0 (SPSS Inc., Chicago, IL).

Descriptive statistics, including mean, standard deviation and frequency distribution, were 
used to describe sample characteristics. In the main analysis, anxiety and depression were treated first as continuous level variables, then as categorical variables. In order to create the categories, variables were created for each individual describing the presence of depression and anxiety using published, standard cut points (10 and 0.35 , respectively). Patients were then divided into the following four groups: 1) patients who had neither depression nor anxiety; 2) patients who had depression; 3) patients who had anxiety; and 4) patients who had comorbid anxiety and depression. Sample socio-demographic and clinical characteristics (i.e., age, gender, ethnicity, NYHA class, anxiety level and depression level) between the four groups were compared using $\mathrm{X}^{2}$ or ANOVA as appropriate to the level of measurement. Hierarchal Cox regression analyses were used to determine whether comorbid symptoms of depression and anxiety, independently, predicted mortality alone, or cardiac rehospitalization alone. Data were forced into the regression in order to provide simultaneous control. The following covariates were considered: age, gender, ethnicity, NYHA class, and anxiety and depression. We first tested the interaction term defining the continuous level variables for anxiety and depression, and the outcomes. We next tested the grouping variables identifying co-morbid depression and anxiety status. The assumptions of hierarchal Cox regression were tested and no violation occurred. A p-value of 0.05 was considered statistically significant.

\section{Results}

Demographic and clinical characteristics of patients $(\mathrm{N}=1,260)$ are summarized in Table 1. The mean levels of anxiety and depression were 0.82 with a SD of $0.92,7.48$ with a SD of 6.22 , respectively. Using the clinically defined cut points, $52.9 \%$ of the participants were anxious and $32.5 \%$ were depressed. When the sample was divided into the four predefined groups, a total of $5.7 \%$ of the patients had depressive symptoms only, $26.1 \%$ had anxiety symptoms only, and $26.8 \%$ had co-morbid symptoms of anxiety and depression. Eighty-two $(6.5 \%)$ of the participants died and $182(14.4 \%)$ were hospitalized during the study.

Hierarchal Cox regression was run with anxiety and depression treated as continuous level variables and all-cause mortality as the outcome. In the first block in which demographic variables were entered, only older age was a significant predictor of all-cause mortality. In the second block, NYHA class was entered to the model. Age remained a significant predictor. Additionally, worse NYHA functional class was a significant predictor in this block. In the final block, age (HR 1.03; 95\% CI: 1.01-1.05; $\mathrm{p}=0.009$ ), worse NYHA class (HR 3.90; 95\% CI: 2.39-6.36; p < 0.001), and higher levels of depression (HR 1.06; 95\% CI: 1.01-1.11; $\mathrm{p}=0.012$ ) were significant predictors of all-cause mortality among HF patients. The interaction between anxiety and depression (HR 1.02; 95\% CI: $1.01-1.03 ; \mathrm{p}=0.002$ ) was also a significant predictor of all-cause mortality. However, anxiety (HR 1.07; 95\% CI: $0.79-1.45 ; \mathrm{p}=0.652$ ) was not a significant predictor of all-cause mortality (Table 2).

Another hierarchal Cox regression was run with anxiety and depression treated as continuous level variables and cardiac rehospitalization as the outcome. In the first block in which demographic variables were entered, older age, female gender, and ethnicity (African Americans compared to Caucasians, and Caucasians compared to other ethnicities) were significant predictors of cardiac rehospitalization. In the second block, NYHA class was 
entered to the model. All previous variables remained significant predictors. Additionally, worse NYHA functional class was a significant predictor in this block. In the final block, anxiety, depression, and the interaction between anxiety and depression were entered to the model. Age (HR 0.99; 95\% CI: 0.97-1.00; $\mathrm{p}=0.016$ ), female gender (HR 1.40; 95\% CI: 1.01-1.94; $\mathrm{p}=0.042$ ), African Americans ethnicity compared to Caucasians ethnicity (HR 2.43; 95\% CI: 1.67-3.54; $<$ 0.001), and Caucasians ethnicity compared to other ethnicities (HR 0.30; 95\% CI: $0.10-0.95 ; \mathrm{p}=0.040$ ), and worse NYHA functional class (HR 2.62; 95\% CI: 1.94-3.55; $\mathrm{p}<0.001$ ) were significant predictors of cardiac rehospitalization among HF patients. However, anxiety (HR 0.93; 95\% CI: 0.75-1.15; $\mathrm{p}=0.505$ ), depression (HR 1.02; 95\% CI: $0.99-1.05 ; \mathrm{p}=0.290$ ), and the interaction between anxiety and depression (HR 1.00; 95\% CI: 1.00-1.01; $\mathrm{p}=0.648$ ) were not significant predictor of cardiac rehospitalization (Table 3).

In the next analysis, anxiety and depression were treated as categorical variables and the four categories previously defined were entered in a hierarchical cox regression to predict all-cause mortality (Table 4). In the first block in which demographic variables were entered, only older age was a significant predictor of all-cause mortality. In the second block, NYHA class was entered to the model. Age remained a significant predictor. Additionally, worse NYHA functional class was a significant predictor in this block. In the final block, the four anxiety and depression groups were entered into the model. The final model demonstrated that that older age, worse NYHA class, and comorbid anxiety and depression were the significant predictors of all-cause mortality. In this analysis neither anxiety alone or depression alone were significant predictors of all-cause mortality among HF patients (Figure 1). Based on these results, HF patients with comorbid anxiety and depression are 2.6 times more likely to die compared to those who are neither depressed nor anxious (Table 4 and Figure 1).

A final hierarchical Cox regression was used where anxiety and depression were treated as categorical variables to predict cardiac rehospitalization (Table 5). In the first block in which demographic variables were entered, older age, female gender, African American ethnicity compared to Caucasian, and Caucasian ethnicity compared to other ethnicities were significant predictors of cardiac rehospitalization. In the second block, NYHA class was entered to the model. Age, gender, and ethnicity remained significant predictors. Additionally, worse NYHA functional class was a significant predictor in this block. In the final block, the four anxiety and depression groups were entered into the model. The final model demonstrated that that older age, female gender, African American ethnicity compared to Caucasian, Caucasian ethnicity compared to other ethnicities, and worse NYHA class were the significant predictors of cardiac rehospitalization. In this analysis neither anxiety alone, depression alone, or comorbid anxiety and depression were significant predictors of cardiac rehospitalization among HF patients (Table 5 and Figure 2).

\section{Discussion}

Several important findings are evident from this study. First, anxiety and depressive symptoms are common and are commonly comorbid in patients with HF. The majority of our sample experienced symptoms of depression or anxiety, or both. Second, we 
demonstrated that comorbid anxiety and depressive symptoms, when considered as a clinically relevant categorical variable, was predictive of all-cause mortality, while anxiety and depressive symptoms considered alone were not independent predictors of the same outcome. When treated as continuous level variables, both comorbid depression and anxiety, and depression alone were significant predictors of all-cause mortality. None of the psychological variables were predictive of the cardiac rehospitalization outcome, regardless of whether entered as continuous or categorical level variables. The findings of this study emphasize the hazardous effects of comorbid anxiety and depressive symptoms on the mortality rate of adults with HF.

More than 50\% of HF patients suffer from significant symptoms of anxiety or depression (7, $22,23)$. HF patients' mortality rate is around $40 \%$ within the first year of diagnosis despite current medical and surgical advances $(2,3)$. Because anxiety and depression have been consistently associated with poorer health outcomes $(24,25)$, we wanted to examine whether they also explained the high rates of mortality among HF patients.

This study is one of few to investigate comorbid anxiety and depression and its effect on allcause mortality and cardiac rehospitalization in patients with HF. Frasure-Smith and colleagues found that anxiety and depression were associated with cardiac mortality using a single instrument (the General Health Questionnaire-20) to assess psychological distress. However, these researchers did not control for disease severity, age, and other risk factors. In addition, the additive effect of anxiety and depression was not studied (36). In another study by Doering and colleagues (37), researchers focused on mortality and demonstrated that co-morbid anxiety and depression were predictive of all-cause mortality in patients with coronary artery disease, but did not study hospitalizations. Doering et al. also used the Multiple Adjective Affect Checklist (MAACL-D) to measure depression (37). However, in the HF population, the PHQ-9 is considered one of the best instruments to measure depression $(31,32)$. In addition, Doering et al treated depression and anxiety as a categorical variables without consideration of these variables treated at the continuous level, which may mask expression of the phenomenon.

Our study is unique in its focus on comorbid anxiety and depression and its effect on cardiac rehospitalization and mortality for all causes in HF patients. Our strengths included the use of valid and reliable instruments to measure depression and anxiety symptoms in patients with HF, and a large sample size. Furthermore, we treated anxiety, depression, and both as continuous-level and categorical-level variables, and we controlled for multiple covariates such as age, gender, etyhincity, and NYHA class.

Our study showed that depression alone, and the interaction of depression and anxiety are the only significant psychological predictors of all-cause mortality among HF patients when we included continuous measures of anxiety, depression, and the interaction between anxiety and depression in our model. When we conducted the analysis using categorical variables, we found that comorbid anxiety and depression was the only significant psychological predictor; neither anxiety nor depression alone was a significant predictor. For depression alone, the lack of significance may be explained by the low number of individuals who had depression alone $(\mathrm{n}=72)$. However, when we run the analysis again 
using an unadjusted model, depression alone (HR 2.53; 95\% CI: 1.04-6.16; $\mathrm{p}=0.042$ ) was a significant predictor of all-cause mortality among HF patients. This finding suggests that sample size alone does not explain the failure of depression to independently predict the outcome, but rather, suggests that depression, in the company of other psychological, demographic and clinical predictors of outcomes, depression alone is not an independent predictor.

Our results that psychological factors are important mechanisms for the high mortality rate in HF. Anxiety and depression are strongly associated with unhealthy practices such as smoking, drinking, and unsatisfactory patient compliance $(12,13)$. They are also associated with physiological changes that can lead to hospitalization and death such as hypercortisolemia, impaired platelet function, reduced heart rate variability, cardiac arrhythmias, and sudden death (14-17),(19-21). Thus, these behavioral and physiological factors associated with anxiety and depression likely contribute to the continuing high morbidity and mortality in HF.

\section{Study limitations}

A potential limitation of our study was the use of self-reported measurement of symptoms of anxiety and depression, rather than diagnostic interviews. However, a strict protocol was used to measure anxiety and depression, and we and others have previously demonstrated the reliability and validity of the self-report instruments used in patients with HF (38-41). Another possible limitation was the absence of treatment, and failure to adjust for some covariate such as smoking and alcohol consumption that may contribute to the phenomena. However, the major covariates, age, gender, ethnicity, and NYHA class, were controlled for in this study. This, along with the large sample size, are strengths of the study.

\section{Conclusion}

Our findings have clinical and research implications. Comorbid anxiety and depression symptoms are a better predictor of death in HF patients than anxiety or depression alone. Thus, to improve outcomes in patients with HF, attention must be paid by healthcare providers to the assessment and management of co-morbid symptoms of depression and anxiety. Future studies should investigate and evaluate strategies or methods that able to screen and treat depression and anxiety symptoms in HF patients effectively.

\section{Acknowledgements}

This work was supported by the National Institutes of Health, National Institute of Nursing Research [R01 NR008567 to D.K.M., R01 NR009280 to T.A.L., P20NR010679 to D.K.M, and K23 NR013480 to R.L.D.]. The content is solely the responsibility of the authors and does not necessarily represent the official views of the National Institute of Nursing Research or the National Institutes of Health. Financial sponsors played no role in the design, execution, analysis, and interpretation of data or writing of the study.

\section{References}

1. Roger VL, Go AS, Lloyd-Jones DM, Adams RJ, Berry JD, Brown TM, et al. Heart disease and stroke statistics--2011 update: a report from the American Heart Association. Circulation. 2011; 123(4):e18-e209. [PubMed: 21160056] 
2. Adams KF Jr. Zannad F. Clinical definition and epidemiology of advanced heart failure. Am Heart J. 1998; 135(6 Pt 2 Su):S204-15. [PubMed: 9630086]

3. MacMahon KM, Lip GY. Psychological factors in heart failure: a review of the literature. Arch Intern Med. 2002; 162(5):509-16. [PubMed: 11871918]

4. Bennett SJ, Pressler ML, Hays L, Firestine LA, Huster GA. Psychosocial variables and hospitalization in persons with chronic heart failure. Prog Cardiovasc Nurs. 1997; 12(4):4-11. [PubMed: 9433728]

5. Barlow, D. Anxiety and its disorders. Guilford Press; New York: 1988.

6. Seligman, L. Selecting effective treatments: a comprehensive systematic guide to treating mental disorders. Jossey-Bass; San Francisco: 1998.

7. Konstam V, Moser DK, De Jong MJ. Depression and anxiety in heart failure. J Card Fail. 2005; 11(6):455-63. [PubMed: 16105637]

8. Blazer DG, Kessler RC, McGonagle KA, Swartz MS. The prevalence and distribution of major depression in a national community sample: the National Comorbidity Survey. Am J Psychiatry. 1994; 151(7):979-86. [PubMed: 8010383]

9. Seligman, L. a comprehensive systematic guide to treating mental disorder. Jossey-Bass; San Francisco: 1998.

10. Gottlieb SS, Khatta M, Friedmann E, Einbinder L, Katzen S, Baker B, et al. The influence of age, gender, and race on the prevalence of depression in heart failure patients. Journal of the American College of Cardiology. 2004; 43(9):1542-9. [PubMed: 15120809]

11. Rutledge T, Reis VA, Linke SE, Greenberg BH, Mills PJ. Depression in heart failure a metaanalytic review of prevalence, intervention effects, and associations with clinical outcomes. Journal of the American College of Cardiology. 2006; 48(8):1527-37. [PubMed: 17045884]

12. Ziegelstein RC, Bush DE, Fauerbach JA. Depression, adherence behavior, and coronary disease outcomes. Archives of internal medicine. 1998; 158(7):808-9. [PubMed: 9554689]

13. Carney RM, Freedland KE, Eisen SA, Rich MW, Jaffe AS. Major depression and medication adherence in elderly patients with coronary artery disease. Health psychology : official journal of the Division of Health Psychology, American Psychological Association. 1995; 14(1):88-90.

14. Oldehinkel AJ, van den Berg MD, Flentge F, Bouhuys AL, ter Horst GJ, Ormel J. Urinary free cortisol excretion in elderly persons with minor and major depression. Psychiatry Res. 2001; 104(1):39-47. [PubMed: 11600188]

15. Musselman DL, Tomer A, Manatunga AK, Knight BT, Porter MR, Kasey S, et al. Exaggerated platelet reactivity in major depression. Am J Psychiatry. 1996; 153(10):1313-7. [PubMed: 8831440]

16. Laghrissi-Thode F, Wagner WR, Pollock BG, Johnson PC, Finkel MS. Elevated platelet factor 4 and beta-thromboglobulin plasma levels in depressed patients with ischemic heart disease. Biol Psychiatry. 1997; 42(4):290-5. [PubMed: 9270907]

17. Carney RM, Saunders RD, Freedland KE, Stein P, Rich MW, Jaffe AS. Association of depression with reduced heart rate variability in coronary artery disease. The American journal of cardiology. 1995; 76(8):562-4. [PubMed: 7677077]

18. Rozanski A, Blumenthal JA, Kaplan J. Impact of psychological factors on the pathogenesis of cardiovascular disease and implications for therapy. Circulation. 1999; 99(16):2192-217. [PubMed: 10217662]

19. Kawachi I, Sparrow D, Vokonas PS, Weiss ST. Decreased heart rate variability in men with phobic anxiety (data from the Normative Aging Study). The American journal of cardiology. 1995; 75(14):882-5. [PubMed: 7732994]

20. Lown B, Verrier R, Corbalan R. Psychologic stress and threshold for repetitive ventricular response. Science. 1973; 182(114):834-6. [PubMed: 4795748]

21. Watkins LL, Grossman P, Krishnan R, Sherwood A. Anxiety and vagal control of heart rate. Psychosomatic medicine. 1998; 60(4):498-502. [PubMed: 9710297]

22. Moser, DK.; Dracup, K.; Evangelista, LS.; Zambroski, CH.; Lennie, TA.; Chung, ML., et al. Depression, anxiety, hostility and perceived control in elderly cardiac patients: comparison of prevalence in heart failure, myocardial infarction, coronary artery bypass graft surgery, and healthy elders. 
23. Denollet J, Brutsaert DL. Personality, disease severity, and the risk of long-term cardiac events in patients with a decreased ejection fraction after myocardial infarction. Circulation. 1998; 97(2): 167-73. [PubMed: 9445169]

24. Konstam V, Salem D, Pouleur H, Kostis J, Gorkin L, Shumaker S, et al. Baseline quality of life as a predictor of mortality and hospitalization in 5,025 patients with congestive heart failure. SOLVD Investigations. Studies of Left Ventricular Dysfunction Investigators. The American journal of cardiology. 1996; 78(8):890-5. [PubMed: 8888661]

25. Riedinger MS, Dracup KA, Brecht ML. Predictors of quality of life in women with heart failure. SOLVD Investigators. Studies of Left Ventricular Dysfunction. J Heart Lung Transplant. 2000; 19(6):598-608. [PubMed: 10867341]

26. Moser DK, Heo S, Lee KS, Hammash M, Riegel B, Lennie TA, et al. 'It could be worse ... lot's worse!' Why health-related quality of life is better in older compared with younger individuals with heart failure. Age and ageing. 2013; 42(5):626-32. [PubMed: 23832262]

27. Lee CS, Riegel B, Driscoll A, Suwanno J, Moser DK, Lennie TA, et al. Gender differences in heart failure self-care: a multinational cross-sectional study. Int J Nurs Stud. 2009; 46(11):1485-95. [PubMed: 19442974]

28. Wu JR, Moser DK, Chung ML, Lennie TA. Objectively measured, but not self-reported, medication adherence independently predicts event-free survival in patients with heart failure. $\mathrm{J}$ Card Fail. 2008; 14(3):203-10. [PubMed: 18381183]

29. Kroenke K, Spitzer RL, Williams JB. The PHQ-9: validity of a brief depression severity measure. Journal of general internal medicine. 2001; 16(9):606-13. [PubMed: 11556941]

30. Spitzer RL, Kroenke K, Williams JB. Validation and utility of a self-report version of PRIME-MD: the PHQ primary care study. Primary Care Evaluation of Mental Disorders. Patient Health Questionnaire. JAMA : the journal of the American Medical Association. 1999; 282(18):1737-44.

31. Song EK, Moser DK, Frazier SK, Heo S, Chung ML, Lennie TA. Depressive symptoms affect the relationship of $\mathrm{N}$-terminal pro B-type natriuretic peptide to cardiac event-free survival in patients with heart failure. J Card Fail. 2010; 16(7):572-8. [PubMed: 20610233]

32. Dekker RL, Lennie TA, Albert NM, Rayens MK, Chung ML, Wu JR, et al. Depressive symptom trajectory predicts 1-year health-related quality of life in patients with heart failure. J Card Fail. 2011; 17(9):755-63. [PubMed: 21872146]

33. Derogatis LR, Melisaratos N. The Brief Symptom Inventory: an introductory report. Psychol Med. 1983; 13(3):595-605. [PubMed: 6622612]

34. Khalil A, Hall L, Moser D, Lennie T, Frazier S. The Psychometric Properties of the Brief Symptom Inventory Depression and Anxiety Subscales in Patients With Heart Failure and With or Without Renal Dysfunction. Archives of Psychiatric Nursing. 2011 Article in Press.

35. Moser DK. "The rust of life": impact of anxiety on cardiac patients. American journal of critical care : an official publication, American Association of Critical-Care Nurses. 2007; 16(4):361-9.

36. Frasure-Smith N, Lesperance F. Depression and other psychological risks following myocardial infarction. Archives of general psychiatry. 2003; 60(6):627-36. [PubMed: 12796226]

37. Doering LV, Moser DK, Riegel B, McKinley S, Davidson P, Baker H, et al. Persistent comorbid symptoms of depression and anxiety predict mortality in heart disease. International journal of cardiology. 2010; 145(2):188-92. [PubMed: 19493579]

38. Khalil AA, Hall LA, Moser DK, Lennie TA, Frazier SK. The psychometric properties of the Brief Symptom Inventory depression and anxiety subscales in patients with heart failure and with or without renal dysfunction. Archives of psychiatric nursing. 2011; 25(6):419-29. [PubMed: 22114796]

39. Barth J, Schumacher M, Herrmann-Lingen C. Depression as a risk factor for mortality in patients with coronary heart disease: a meta-analysis. Psychosomatic medicine. 2004; 66(6):802-13. [PubMed: 15564343]

40. van Melle JP, de Jonge P, Spijkerman TA, Tijssen JG, Ormel J, van Veldhuisen DJ, et al. Prognostic association of depression following myocardial infarction with mortality and cardiovascular events: a meta-analysis. Psychosomatic medicine. 2004; 66(6):814-22. [PubMed: $15564344]$ 
41. Hammash MH, Hall LA, Lennie TA, Heo S, Chung ML, Lee KS, et al. Psychometrics of the PHQ-9 as a measure of depressive symptoms in patients with heart failure. European journal of cardiovascular nursing : journal of the Working Group on Cardiovascular Nursing of the European Society of Cardiology. 2013; 12(5):446-53. 


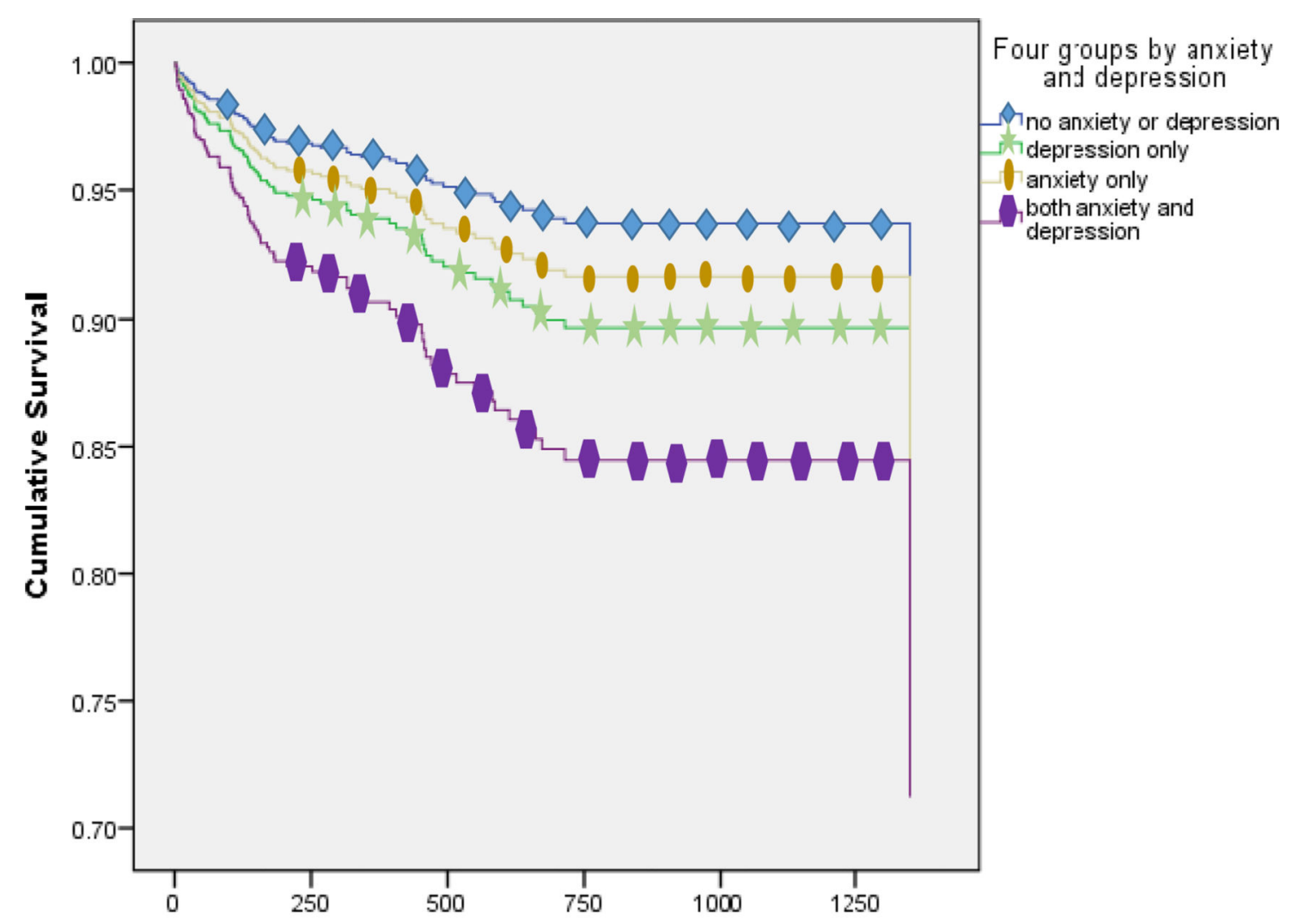

Figure 1. All-cause mortality according to co-morbid symptoms of depression and anxiety

Figure 1.

All-cause mortality according to co-morbid symptoms of depression and anxiety 


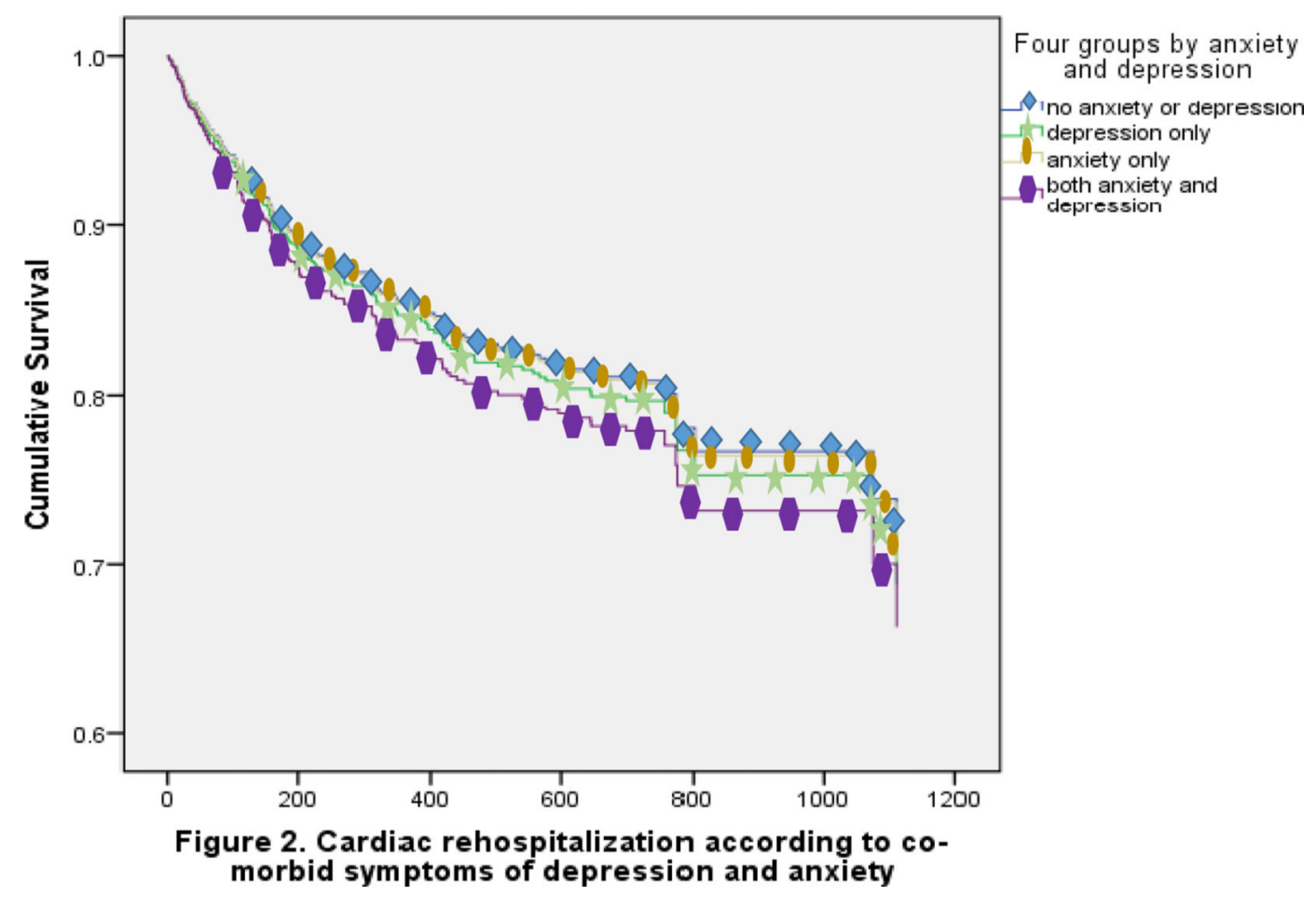

Figure 2.

Cardiac rehospitalization according to co-morbid symptoms of depression and anxiety 


\section{Table 1}

Sample baseline characteristics $(\mathrm{N}=1260)$

\begin{tabular}{lc}
\hline Characteristic & N (\%) OR MEAN \pm SD \\
Age & $63.57 \pm 13$ \\
Anxiety score & $0.82 \pm 0.92$ \\
Depressive symptoms score & $7.48 \pm 6.22$ \\
Gender & \\
$\quad$ Male & $804(63.8)$ \\
Female & $456(36.2)$ \\
Ethnicity & \\
$\quad$ Caucasian & $1017(80.7)$ \\
$\quad$ African American & $153(12.1)$ \\
Other & $90(7.1)$ \\
NYHA class & \\
I/II & $664(52.7)$ \\
III/IV & $596(47.3)$ \\
Anxiety and depression categories & \\
No Anxiety or Depression & $521(41.3)$ \\
Depression Only & $72(5.7)$ \\
Anxiety Only & $329(26.1)$ \\
Co-morbid Anxiety and Depression & $338(26.8)$ \\
\hline
\end{tabular}

Psychosomatics. Author manuscript; available in PMC 2016 July 01. 


\section{Table 2}

Cox proportional hazard regression of variables associated with all-cause mortality in patients with HF, and anxiety and depression treated as continuous level variables.

\begin{tabular}{lccc}
\hline Predictor Variables & Exp.(B) & $\mathbf{9 5 \%} \mathbf{C I}$ & P \\
Age & 1.03 & $1.01-1.05$ & 0.009 \\
Female Gender & 1.06 & $0.67-1.68$ & 0.805 \\
African American compared to Caucasian & 0.30 & $0.07-1.23$ & 0.095 \\
Caucasian compared to ethnicity other than African American & 4.85 & $0.17-1.76$ & 0.315 \\
NYHA class III/IV compared to I/II & 3.90 & $2.39-6.36$ & $<0.001$ \\
Anxiety & 1.07 & $0.79-1.45$ & 0.652 \\
Depression & 1.06 & $1.01-1.11$ & 0.012 \\
Anxiety*Depression & 1.02 & $1.01-1.03$ & 0.002 \\
\hline
\end{tabular}

Overall Model $\left(\chi^{2}=60.08\right.$, df. $\left.=6 ; \mathrm{p}<0.001\right)$ 


\section{Table 3}

Cox proportional hazard regression of variables associated with cardiac event-free survival, defined as the composite of cardiac hospitalization or death due to all causes in patients with HF, and anxiety and depression treated as categorical variables.

\begin{tabular}{lccc}
\hline Predictor Variables & Exp.(B) & $\mathbf{9 5 \%}$ CI & P \\
Block I & & & \\
Age & 1.00 & $0.99-1.01$ & 0.69 \\
Female Gender & 1.29 & $0.99-1.68$ & 0.06 \\
African American compared to Caucasian & 1.78 & $1.25-2.53$ & 0.001 \\
Caucasian compared to ethnicity other than African American & 4.53 & $1.91-10.72$ & 0.001 \\
Block II & & & \\
Age & 1.00 & $0.99-1.01$ & 0.69 \\
Female Gender & 1.28 & $0.98-1.67$ & 0.07 \\
African American compared to Caucasian & 1.80 & $1.25-2.53$ & 0.001 \\
Caucasian compared to ethnicity other than African American & 4.58 & $1.93-10.83$ & 0.001 \\
NYHA class III/IV compared to I/II & 2.98 & $2.31-3.84$ & $<0.001$ \\
Block III (Final Model) & & & \\
Age & 1.00 & $0.99-1.01$ & 0.85 \\
Female Gender & 1.33 & $1.02-1.73$ & 0.04 \\
African American compared to Caucasian & 1.83 & $1.28-2.60$ & 0.001 \\
Caucasian compared to ethnicity other than African American & 4.66 & $1.97-11.04$ & $<0.001$ \\
NYHA class III/IV compared to I/II & 2.78 & $2.14-3.61$ & $<0.001$ \\
Depression Only & 1.22 & $0.71-2.08$ & 0.47 \\
Anxiety Only & 1.10 & $0.80-1.50$ & 0.56 \\
Comorbid Anxiety and Depression & 1.50 & $1.10-2.03$ & 0.01 \\
\hline
\end{tabular}

Overall Model $\left(\chi^{2}=108.18\right.$, df. $\left.=8 ; \mathrm{p}<0.001\right)$ 


\section{Table 4}

Cox proportional hazard regression of variables associated with all-cause mortality in patients with HF, and anxiety and depression treated as categorical variables.

\begin{tabular}{lccc}
\hline Predictor Variables & Exp.(B) & $\mathbf{9 5 \%}$ CI & P \\
Block I & & & \\
Age & 1.01 & $1.00-1.04$ & 0.021 \\
Female Gender & 0.94 & $0.60-1.50$ & 0.806 \\
African American compared to Caucasian & 0.30 & $0.07-1.23$ & 0.094 \\
Caucasian compared to ethnicity other than African American & 0.37 & $0.19-1.88$ & 0.374 \\
Block II & & & \\
Age & 1.02 & $1.00-1.04$ & 0.048 \\
Female Gender & 0.98 & $0.62-1.55$ & 0.929 \\
African American compared to Caucasian & 0.28 & $0.07-1.17$ & 0.081 \\
Caucasian compared to ethnicity other than African American & 0.56 & $0.18-1.77$ & 0.323 \\
NYHA class III/IV compared to I/II & 4.19 & $2.58-6.81$ & $<0.001$ \\
Block III (Final Model) & & & \\
Age & 1.03 & $1.01-1.05$ & 0.006 \\
Female Gender & 0.92 & $0.58-1.45$ & 0.717 \\
African American compared to Caucasian & 0.57 & 0.18 v 1.80 & 0.094 \\
Caucasian compared to ethnicity other than African American & 4.66 & $2.20-5.94$ & 0.335 \\
NYHA class III/IV compared to I/II & 3.62 & $2.14-3.61$ & $<0.001$ \\
Depression Only & 1.67 & $0.68-4.12$ & 0.263 \\
Anxiety Only & 1.35 & $0.74-2.46$ & 0.332 \\
Comorbid Anxiety and Depression & 2.59 & $1.49-4.49$ & 0.001 \\
\hline
\end{tabular}

Overall Model $\left(\chi^{2}=62.78\right.$, df. $\left.=8 ; \mathrm{p}<0.001\right)$ 


\section{Table 5}

Cox proportional hazard regression of variables associated with cardiac rehospitalization in patients with HF, and anxiety and depression treated as categorical variables.

\begin{tabular}{lccc}
\hline Predictor Variables & Exp.(B) & $\mathbf{9 5 \%}$ CI & P \\
Block I & & & \\
Age & 0.99 & $0.98-1.00$ & 0.036 \\
Female Gender & 0.71 & $0.52-0.99$ & 0.040 \\
African American compared to Caucasian & 2.49 & $1.71-3.61$ & $<0.001$ \\
Caucasian compared to ethnicity other than African American & 0.31 & $0.10-0.97$ & 0.044 \\
Block II & & & \\
Age & 0.99 & $0.97-1.00$ & 0.018 \\
Female Gender & 0.71 & $0.52-0.99$ & 0.040 \\
African American compared to Caucasian & 2.44 & $1.69-3.56$ & $<0.001$ \\
Caucasian compared to ethnicity other than African American & 0.30 & $0.10-0.94$ & 0.040 \\
NYHA class III/IV compared to I/II & 2.60 & $1.60-3.50$ & $<0.001$ \\
Block III (Final Model) & & & \\
$\quad$ Age & 0.99 & $0.97-0.99$ & 0.035 \\
Female Gender & 0.70 & $0.51-1.97$ & 0.034 \\
African American compared to Caucasian & 2.47 & $1.70-3.61$ & $<0.001$ \\
Caucasian compared to ethnicity other than African American & 0.30 & $0.10-0.95$ & 0.040 \\
NYHA class III/IV compared to I/II & 2.52 & $1.85-3.43$ & $<0.001$ \\
Depression Only & 1.07 & $0.55-2.09$ & 0.847 \\
Anxiety Only & 1.01 & $0.70-1.47$ & 0.953 \\
Comorbid Anxiety and Depression & 1.18 & $0.81-1.71$ & 0.391 \\
\hline
\end{tabular}

Overall Model $\left(\chi^{2}=88.59\right.$, df. $\left.=8 ; \mathrm{p}<0.001\right)$ 